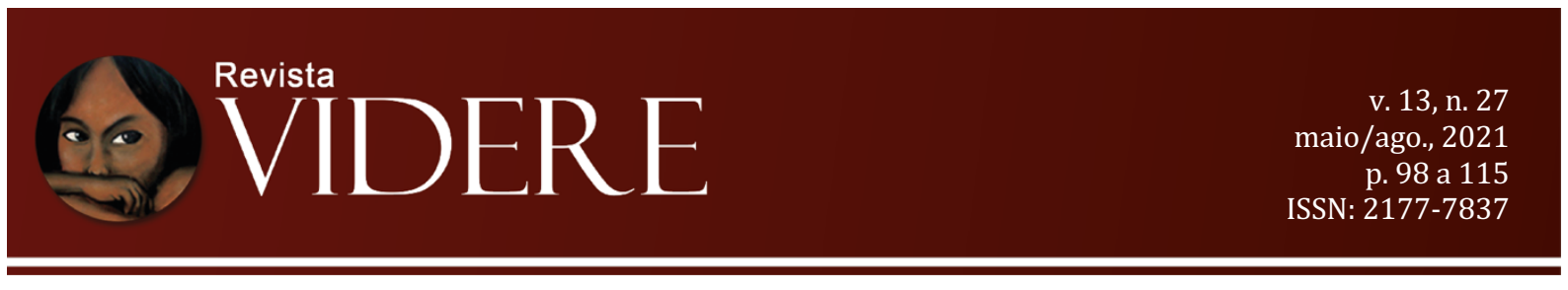

\title{
A “MULTIDÃO” HARDT-NEGRIANA: APONTAMENTOS CRÍTICOS
}

\author{
THE HARDT-NEGRIAN “MULTITUDE”: CRITICAL NOTES \\ LA “MULTITUD” DE HARDT-NEGRIANA: NOTAS CRÍTICAS
}

Fernando Nogueira Martins Júnior

Doutor em Direito pela Universidade Federal de Minas Gerais Professor da Universidade Federal de Lavras - UFLA fernando.martins@ufla.br OrcidID: http://orcid.org/ 0000-0003-0327-9951

\begin{abstract}
Resumo: O texto apresenta, em linhas gerais, o conceito de "Multidão" desenvolvido nas obras do filósofo italiano Antonio Negri e do teórico literário norte-americano Michael Hardt. O entendimento da "Multidão" como novo "sujeito" revolucionário, formado por singularidades cooperativas e não-unificadas (em nenhuma instância), instiga a muitos e levanta críticas de tantos outros. O artigo apresenta algumas críticas ao conceito de "Multidão", especialmente por seu afastamento/denúncia acerca da categoria de classes sociais, por sua imprecisão conceitual, por sua construção discursivo-filosófica apartada de dados empíricos sólidos e por sua aposta na espontaneidade das massas revoltosas que, sem qualquer organização política mais consistente, seriam aptas a fazer avançar uma Revolução.
\end{abstract}

Palavras-chave: Multidão. revolução. sujeito. classes sociais. espontaneidade.

\begin{abstract}
The text presents, in general lines, the concept of "Multitude" developed in the works of the italian philosopher Antonio Negri and of the north-american literary theoricist Michael Hardt. The understanding of the "Multitude" as a new revolutionary subject, formed by cooperative and non-unified (on any stance) singularities, instigates many and raises criticism of many others. The article presents some of the criticism towards the concept of "Multitude", especially for its withdrawal/denunciation regarding the category of social classes, for its conceptual imprecision, for its discursive-philosophical construction departed from solid empirical data and for its wager on the spontaneity of the rebellious masses that, without any more consistent political organization, would be able to move forward a Revolution.
\end{abstract}

Keywords: Multitude. revolution. subject. social classes. spontaneity.

Resumen: El texto presenta, en líneas generales, el concepto de "Multitud" desarrollado en las obras del filósofo italiano Antonio Negri y del teórico literario norteamericano Michael Hardt. 
La comprensión de la "Multitud" como un nuevo "sujeto" revolucionario, formado por singularidades cooperativas y no unificadas (en ningún caso), instiga a muchos y suscita críticas de muchos otros. El artículo presenta algunas críticas al concepto de "Muchedumbre", especialmente por su alejamiento / denuncia de la categoría de clases sociales, su imprecisión conceptual, su construcción discursivo-filosófica separada de datos empíricos sólidos y su apuesta por la espontaneidad de lo rebelde. masas que, sin una organización política más consistente, podrían hacer avanzar una Revolución.

Palabras clave: Multitud. revolución. tema. clases sociales. espontaneidad.

\section{Introdução}

Vivemos no Brasil o post factum de uma derrota histórica e estratégica, que relegou todo o campo progressista a uma posição (ainda) defensiva frente ao avanço de uma ultradireita que, orgulhosa de sua abissal abjeção e desumanidade, ocupou vários espaços de poder dentro e fora das instituições do Estado.

Ainda faremos o balanço deste notável fato histórico, para o qual muitos fatores contribuíram, à revelia da esquerda e, vale dizer, por causa desta mesma esquerda. É dizer, cremos que é razoável apontar que, dentre os diversos elementos que levaram água no moinho da completa incapacidade da esquerda brasileira em resistir e articular uma contraofensiva frente ao avanço do bolsonarismo e da agressão imperialista que o apoia e pilota, há a indigência teórico-prática dos setores ditos "à esquerda" do espectro político.

Uma das facetas principais da "terra arrasada" da esquerda institucional e parainstitucional é, de fato, o pós-modernismo na formulação e na militância, que se alastrou por todo o Brasil. As implicações gerais disso já foram tratadas com qualidade por autores consagrados (vide, a título meramente ilustrativo, HARVEY, 1992; EAGLETON, 1998; EAGLETON; 2016; JAMESON, 2006; JAMESON, 2013).

O objeto do presente trabalho é uma manifestação em específico do pós-modernismo político, qual seja, o pensamento de Antonio Negri e Michael Hardt (a partir de agora chamado por vezes de "hardt-negrianismo"). Ainda, em uma delimitação ainda mais estrita do objeto, trararemos do conceito de "multidão" na obra dos dois conhecidos autores ditos "esquerdistas". Tomamos isto como objeto de investigação pela relevância que este pensamento - e seus desdobramentos práticos - tem, desde há muitos anos, no Brasil. Onde quer que, na academia e nos movimentos sociais brasileiros, haja uma posição "de esquerda" que seja contra o marxismo metodologicamente ortodoxo ou mesmo contra o comunismo de cepa marxista- 
leninista, as chances de esta posição ser oriunda da adoção da teoria vertida nas obras de Negri e Hardt são imensas.

Através de uma reflexão que mobiliza várias fontes bibliográficas devidamente revisadas, analisaremos a "multidão" hardt-negriana por meio da delimitação do conceito e dando ênfase às críticas feitas por pensadores filiados não só ao marxismo, mas também ao pósmarxismo.

A reflexão também parte da vivência militante de quem realiza a presente pesquisa, vivência esta que proporcionou uma visão em primeira mão dos efeitos - principalmente deletérios - que o pensamento de Hardt e Negri tiveram na luta social concreta encampada por partidos e organizações. Portanto, os resultados da pesquisa apresentados abaixo mostram o final de uma reflexão (sempre provisória e aberta ao falseamento, é certo) que reconhece os graves problemas que tal marco teórico-prático trouxe e vem trazendo para lutadores e lutadoras sociais em nosso país.

\section{A obra de Negri (e Hardt) ora em comento}

Antonio Negri, filósofo italiano e ex-militante autonomista, de longa e prolífica e produção teórica, junta-se a um de seus pupilos, o teórico literário norte-americano Michael Hardt, para escrever, entre outros livros, a trilogia "Empire/Império" (HARDT; NEGRI, 2001), "Multitude/Multidão" (HARDT; NEGRI, 2005) e "Commonwealth/Bem-Estar Comum" (HARDT; NEGRI, 2016).

O conceito de Multidão ("Multitude") é ventilado no primeiro livro da trilogia, desenvolvido no segundo e utilizado também no terceiro - e no restante da obra posterior dos autores. Esse conceito, hoje bastante conhecido, informa as mais diversas discussões em matéria de filosofia política (e mesmo filosofia dita "radical") ${ }^{1}$, e embasa várias iniciativas de intervenção política no Brasil e no mundo².

Isto posto, nossa análise passará por vários textos e falas dos autores, e circulará notadamente também por entre a literatura crítica, que já escreveu - e vem escrevendo - sobre

\footnotetext{
${ }^{1}$ P. ex., MENDES; CAVA, 2017.

${ }^{2}$ P. ex., a chamada "Rede Universidade Nômade" (ou UNINÔMADE) que, segundo sua própria descrição, "é uma rede transnacional, que se compõe de militantes, intelectuais, artistas, grupos de pesquisa, coletivos, ativistas de cursinhos pré-vestibulares populares, blogues, e pontos em geral dispersos em redes sociais, produtivas e colaborativas. É também um estilo de militância, baseado nos conceitos de multidão, enxame, êxodo e produção do comum, que se organiza e nomadiza de um modo autônomo, independentemente de um centro orgânico, uma "sede" ou qualquer tipo de organização rígida de princípios, membros ou diretivas." Vide UNINÔMADE BRASIL, 2020.
} 
o tema. A mudança, de Karl Marx para Baruch de Espinosa, do eixo principal de embasamento da teoria revolucionária dita "marxista", e a promoção da filosofia e em especial do direito a um primeiro plano de análise e proposição, ficando a economia política em segundo plano ${ }^{3}$, gerou e gera muitas e ricas polêmicas.

Convidamos o leitor deste trabalho a encontrar a obra completa de Negri e Hardt, para que por si faça o juízo crítico. O presente trabalho não comportaria uma análise de tal fôlego, que cobrisse a inteireza da obra dos autores em baila.

O que se vê abaixo é uma apresentação do tratamento crítico de um dos pontos da obra hardt-negriana: a "Multidão" como, mutatis mutandis, um "sujeito político".

\section{3 "Multidão"?}

Um novo "sujeito" revolucionário se mostra ao mundo: a Multidão. Em um reação homóloga e simétrica à hipermundialização do governo, do controle social e dos fluxos do capital - que tornaria obsoleta a categoria de "imperialismo" e ensejaria o advento do "Império" universal ${ }^{4}$ - surgiria uma "Multidão" também universal, para além de fronteiras nacionais, linguísticas ou outras, que apontariam para o campo de uma "resistência global". Um "sujeito" revolucionário planetário.

Nas palavras de Antonio Negri e Michael Hardt - a partir de agora, N\&H (2004, p. 139), “A ação política voltada para a transformação e a libertação só pode ser conduzida hoje com base na multidão."

Fica, pois, a pergunta: o que vem a ser "Multidão"?

A multidão (...) não é unificada, mantendo-se plural e múltipla (...). A multidão é composta de um conjunto de singularidades - e com singularidades queremos nos referir aqui a um sujeito social cuja diferença não pode ser reduzida à uniformidade, uma diferença que se mantém diferente. (HARDT; NEGRI, 2004, p. 139)

"Uma diferença que se mantém diferente". Em uma reação à sanha uniformizante de partidos revolucionários de extração leninista (ou, para alguns, stalinista), em uma reação às sociedades ditas de "socialismo real" - onde a garantia dos direitos sociais por vezes impunha

\footnotetext{
${ }^{3}$ Negri tem como referência central em Marx, basicamente, um único momento da teoria marxiana, qual seja, o "fragmento sobre as máquinas", trecho dos Grundrisse, e que contrariaria as proposições do dito "Marx maduro", constantes de sua obra maior, "O Capital". Para o referido fragmento, vide MARX, 2011.

${ }^{4}$ Tese sumamente polêmica, que já provocou várias respostas por parte de marxistas de todo o mundo. Por todos, BORÓN, 2004; TURCHETTO, 2003; KOHAN, 2006.
} 
uma substancial restrição de direitos individuais, $\mathrm{N} \& \mathrm{H}$ pugnam pelo reconhecimento de um conjunto de singularidades, de individualidades fluídas, mutantes, intercambiáveis, que juntas, unidas (e não unificadas) massivamente mas não como massa, teriam o condão de se coordenarem e de se insurgirem, amplamente, em escala global, contra o Império, em uma "revolução comunista de novo tipo" que faria a passagem de uma sociedade capitalista global imperial para uma sociedade global comunista - sem necessidade de qualquer estágio parecido com o "socialista" preconizado pelos marxistas clássicos.

A Multidão é plural, singular, idiossincrática, resistente molecular e corporalmente aos ditames unificadores do Capital - e de tantas outras instituições e proposições que sob ele (os autores afirmam) replicam dinâmicas de controle, disciplina, organização - de biopoder, foulcautianamente falando (como, de fato, N\&H se expressam). Para eles, por exemplo, "as singularidades plurais da multidão contrastam, assim, com a unidade indiferenciada do povo" (HARDT; NEGRI, 2004, p. 139).

Pode-se dizer, ab initio, que para os autores o "povo" - este "significante vazio", nas palavras de Ernesto Laclau (LACLAU, 2013) e de Chantal Mouffe (MOUFFE, 2019) - que em outros tempos serviu tanto para a manipulação chauvinista e belicista quanto para as lutas de libertação nacional anticoloniais e anti-imperialistas, nunca serviu para fins de revolução. A ideia - e a prática - de povo sempre teria buscado a unificação "transcendental" do plural, a conformação de singularidades em uma dinâmica, uma identidade e uma - possibilidade de representação, o que a tornava passível de disciplinamento, de controle e de "normalização". Ao contrário, a Multidão romperia com este supostamente "retrógrado" referencial organizacional $^{5}$. Na sua impossibilidade de unidade e unificação a Multidão é "presentável" tão somente (e não representável), como um "belo monstro" incompreensível pela racionalidade vulgar moderna - é preciso o (ir)racionalismo pós-moderno para se entender (mas nunca apreender) o que é a Multidão:

Em um sentido mais geral, a multidão desafia qualquer representação por se tratar de uma multiplicidade incomensurável. O povo é sempre representado como unidade, ao passo que a multidão não é representável, ela apresenta sua face monstruosa vis-à-vis os racionalismos teleológicos e transcendentais da modernidade. (NEGRI, 2004, p. 17)

\footnotetext{
5 N\&H afastam também qualquer homologia da "Multidão" com outras concepções, como "massa", "plebe", "turba”, "populacho". Para maiores elementos, vide, p.ex., a Parte 2 de HARDT; NEGRI, 2005.
} 
A fragmentação social dos novos tempos pós-modernos daria azo a uma dissolução de antigas identidades, dando abertura por conseguinte uma miríade "rizomática" de identidades autorreferenciadas, singularidades e "únicos", que apontariam a nossas formas de resistência e de subversão da ordem do Capital.

Para Giuseppe Cocco (2007, p. 79), cientista político italiano, adepto de Negri e radicado no Brasil:

Com ela [a fragmentação social] desmoronam as tradicionais identidades, formas de organização sindical e dinâmicas da representação política. Isso se reflete no declínio dos movimentos sociais organizados e, dentro deles, dos ligados ao movimento operário (os sindicatos).

O novo "sujeito social", portanto, é reconhecido no esteio de um resgate da filosofia de Baruch de Espinosa: é algo de uma "imanência", oriundo do "ser" do mundo, sem mediações (linguísticas, sociais, etc). Para Negri (2004, p.15) "Multidão é o nome de uma imanência. A multidão é um conjunto de singularidades."

Como bem põe Malcolm Bull (2001), crítico de arte britânico, para H\&N “o político é 'uma multidão de singularidades cooperativas' coextensiva com o social, mas não mediada através deste."

Entretanto, para além de uma proposição espinosista de "imanência" "plural" de "singularidades", a "Multidão" é inserida no contexto do pensamento de Karl Marx (ainda que de forma seletiva, como veremos à frente), e se presta a ter um rendimento enquanto compreendida como classe:

A multidão é um conceito de classe. Com efeito, a multidão é sempre produtiva e está sempre em movimento. Considerada a partir de uma perspectiva temporal, a multidão é explorada pela produção; de um ponto de vista espacial, a multidão é ainda explorada, na medida em que constitui a sociedade produtiva, a cooperação social para a produção. (NEGRI, 2004, p. 15)

A inserção da Multidão no processo de produção e reprodução da vida social é, portanto, garantida. A Multidão - como as classes subalternas de ontem - é um dos articuladores privilegiados da dinâmica exploratória e concentradora do capital.

Todavia, a Multidão como "classe" se dá de forma diferente da concepção marxista clássica. Ela é além - e aquém - dos trabalhadores enquanto produtores da riqueza social; ela não tem qualquer marcação de identidade de classe, ou de qualquer organização pelo antagonismo frente a outra classe cujos interesses são inconciliáveis com o "sujeito" 
revolucionário (ainda que modificado, ampliado, para agregar o "lúmpen" e tantos outros "condenados da terra"6) A Multidão não só se coloca como mais ampla do que o núcleo social proletário "ortodoxo" - enquanto operários fabris - mas pode mesmo prescindir desses operários: a Multidão, enquanto imanência potencialmente revolucionária, não inclui necessariamente os produtores de riqueza em âmbito industrial; a classe aqui é todos os que participam da cooperação produtiva social (aqui se entendendo a produção não só de riquezas no sentido mais corrente, mas também de afetos e ideias) - ainda que se vislumbre a possibilidade de se excluir de alguma forma o operariado fabril dessa Multidão, uma vez que sua presença não é necessária, nas palavras de Negri:

O conceito de classe aplicado à multidão deve ser visto de um ângulo diferente do conceito de classe trabalhadora. "Classe trabalhadora" é um conceito limitado, tanto pelo aspecto da produção (já que necessariamente inclui operários de fábrica), quanto pelo lado da cooperação social (uma vez que compreende apenas uma pequena parcela de trabalhadores que operam no conjunto da produção social). (NEGRI, 2004, p. 16)

Ainda: na compreensão hardt-negriana de "exploração da Multidão", muito da economia política crítica desenvolvida por Marx e pelos que vieram após deve ser afastado. A articulação da exploração do trabalhador através da extração de mais-valia - e sua incorporação em outros setores da economia, como o de tecnologia e de serviços e como formas de incremento da reprodução ampliada do Capital e de aumento da produtividade com fins de geração de mais-valia relativa - é um tanto deixada de lado, para se dar ênfase ao que o "hardtnegrianismo" postula como "exploração da cooperação":

Se postularmos a multidão como um conceito de classe, precisamos redefinir a noção de exploração como exploração da cooperação: cooperação não de indivíduos, mas de singularidades, exploração do conjunto de singularidades, das redes que compõem o conjunto e do conjunto que abarca estas redes e assim por diante. (NEGRI, 2004, p. 16)

\footnotetext{
6 "De acordo com os marxistas, o lumpenproletariado, ou 'slum proletariat', consiste nos membros os mais rebaixados de uma sociedade industrial - excluídos, pedintes, mendigos, andarilhos, pequenos criminosos, pessoas não empregáveis etc. Durante um período de depressão econômica, jovens que não podem ser acomodados no mundo do trabalho podem ser forçados a compor esta classe por uma completa ausência até mesmo de 'empregos para proletários'. O lumpenproletariado padece de uma falta de consciência de classe (diferentemente do proletariado), e é basicamente 'jogado de um lado para o outro' [pushed around] pela burguesia (possivelmente porque o dinheiro provido pela burguesia seja o único meio de subsistência daquele, gerando portanto uma desnecessidade de revolta contra esta)." MARXWIKI, 2020. Tradução livre. Registre-se que tendemos a discordar desta interpretação típica do marxismo mais claśsico, a qual não seria tão precisa, notadamente em um contexto (neo)colonial. Alinhamo-nos mais com a compreensão de Frantz Fanon sobre o tema. Vide FANON, 2006.
} 
A Multidão, conteúdo "vivo" de uma outra concepção de "classe", abre espaço para um outro instrumental teórico para se compreender o que vem a ser esse novo "sujeito" revolucionário. A imanência espinosista, do "agora", do que "é", do "presente", rompe com a base histórico-dialética do marxismo e, com um otimismo arrebatador, afirma que os novos tempos da globalização indicam uma revolução global, realizada por uma resistência imanente também global, por singularidades em rede em escala planetária.

O discurso de Negri, ao menos interpretado assim, participa - segundo modalidades próprias, com seus conceitos particulares da "classe", hoje referida ao intelecto geral, da "época", como a das "multinacionais" etc. que podemos considerar mais ou menos consistentes - desse novo rumo do marxismo que, resistente ao desespero de um horizonte histórico tornado indiscernível, procura, fora de todo historicismo, no presente do evento (social, cultural etc.), no sentido e não no termo, na imanência spinozista, na presença e na garantia do fim. (BIDET, 2004, p. 97)

A teoria hardt-negriana da "Multidão" vem sendo desenvolvida por Negri, Hardt e uma legião de seguidores nos mais diversos países. Movimentos autonomistas e libertários, "tribos" urbanas e tantos outros núcleos, momentos e movimentos ditos anticapitalistas vêm tomando para si os conceitos construídos na trilogia hardt-negriana e em tantos outros trabalhos.

Pois bem. Após a apresentação do conceito na obra de N\&H, vêm os críticos que instauram um embate teórico - com consequências práticas, diga-se - digno de nota.

O presente texto, como já colocado, vem no sentido de expor estas críticas - com as quais, vale dizer, concordamos. É o que segue.

\section{A Multitude Multitudinária da Multidão: Algumas Críticas ${ }^{7}$}

Um caso relatado pelo militante trotskista argentino Juan Dal Maso (2014) é bastante ilustrativo do tom que várias críticas relevantes à "Multidão" de N\&H recebem:

Há cinco anos [Obs: Juan está em 2008 quando escreve o texto], perguntei a Toni Negri em uma conversa [charla] se ele considerava que se podia analisar a situação latinoamericana, em particular o processo de luta na Bolívia, utilizando sua ideia de uma multidão que incluiria uma multiplicidade de sujeitos que se constituem como tais no momento do evento. Dado que os aimaras têm 500 anos de luta e os mineiros [bolivianos] quase um século, e

\footnotetext{
${ }^{7}$ Este artigo não tem - nem poderia ter - o escopo de apresentar todas as vertentes de críticas feitas ao trabalho de Negri e Hardt, pois são muitas e bem variadas, e tocam quase todas as propostas da obra. Como o assunto deste escrito é uma dessas concepções, a de "Multidão", essa seção do artigo pretende apresentar uma amostragem significativa do que se discute criticamente sobre o tema.
} 
ambos se reconhecem com identidades muito marcadas, parecia mais que duvidoso. Sua resposta foi que não conhecia o processo boliviano, pelo que não poderia responder. A conversa na fábrica Grissinópoli terminou porque Negri tinha que ir a um jantar com o grupo Michelangelo, que incluía vários funcionários do governo de Néstor Kirchnner.

Apesar de Negri ter passado a opinar sobre a América Latina e suas $\operatorname{lutas}^{8}$, nota-se que sua formulação acerca da "Multidão" surge em um primeiro momento sem se analisar o ciclo de lutas que, mais recentemente, tem dado o tom das lutas ampliadas contra a dominação imperialista (ou "imperial") e em defesa de culturas centenariamente massacradas: os processos de mobilização e ruptura na Bolívia, no Equador e, de forma diferenciada, na Venezuela.

Enquanto as amplas lutas na América Latina eletrizavam a esquerda revolucionária de todo o mundo, Negri - mesmo se reconhecendo um comunista de talhe marxista - tomou como referencial para sua teoria as movimentações neoanarquistas dos dias de Ação Global (Seattle, Gênova, etc) e seus grupos de contestação (squatters, Tutti Bianchi, comunalistas neo-hippies, etc).

Portanto, uma das críticas levantadas à obra de Negri é a de "eurocentrismo". Não a desenvolveremos, pois outras críticas, atinentes à estrutura do conceito ora em comento, veiculam satisfatoriamente as insuficiências que tem como uma de suas causas a visão eurocêntrica da luta social.

Uma outra proposição crítica, já na "imagem invertida e simétrica da Multidão" que é o "Império" ("global", "acêntrico", "rizomático" até), mostra, a nosso ver, como N\&H simplesmente não veem como a assimetria entre os diversos Estados nacionais ainda é relevante para compreender como o capitalismo globalizado opera. As consequências das mais que atuais concepções de "capitalismo central" e "capitalismo periférico", de "dependência", de “desenvolvimento desigual e combinado", de "imperialismo" são visíveis, vistas e sentidas a olho nu e na carne, nos corpos dos indivíduos que residem no sul do globo. A abstração ínsita ao conceito de Império torna um tanto opaca - e, por que não, hiperidealizada - a possibilidade de análise - e de superação - da subordinação dos países dependentes, antes chamados de "terceiro mundo".

\footnotetext{
${ }^{8}$ Vide, entre outros, COCCO; NEGRI, 2005.

${ }^{9} \mathrm{~N} \& \mathrm{H}$, com uma retórica linguística e filosoficamente relativista, informa a todos(as) que "o primeiro mundo existe no terceiro mundo, e o terceiro mundo existe no primeiro mundo" - bolsões de prosperidade em meio à miséria, bolsões de miséria em meio à prosperidade (HARDT; NEGRI, 2005. p. 213-215). Contudo, tal constatação tem pouco rendimento analítico, uma vez que é tomada como dado óbvio para as mais diversas teorias que, seguindo um caminho marxista menos heterodoxo, buscam compreender a dinâmica capitalista global mais metódica e cientificamente, e menos filosoficamente. Vide as ricas categorias de "burguesia proconsular/compradora", ou de "guetificação", ou mesmo de "colonialismo interno".
} 
Isto posto, é interessante verificar as consequências da "hiperfilosofização" de elementos e dinâmicas já tratados pela ciência política, pela economia, pela geografia e pela história. Com o advento do "Império global", sem centros, em rede, indiferenciado em última instância (ainda que contando com mutáveis "núcleos-força", com "nós" de poderio na rede mundial), surge a também global, acêntrica e rizomática contraparte-parelha: a "Multidão". E, como o Império, a Multidão é indistinta em sua composição múltipla de singularidades radicais. O que é hoje singularidade com um certo conteúdo, muda no momento seguinte, e passar e transpassa barreira culturais, raciais, de gênero, de identificação sexual. Tudo transita na rede mutante de singularidades multitudinárias. Efeito direto disso é que "assim, subitamente/em uma 'canetada' [de um plumazo], desapareceram da cena as classes sociais e se evaporou a distinção entre exploradores e explorados e entre débeis e poderosos" (BORÓN, 2004, p. 110).

Que fazer, então? N\&H tendem a postular que a Multidão, cooperativa e composta das singularidades radicais, enfrentariam, como resultado de sua imanência mesma, o Império, se libertando mormente através do que os autores chamam de "Êxodo": o abandono do Império, de seus ditames sociais, das redes de determinação, condicionamento, subordinação e disciplina - de suas máquinas identitárias e normalizadoras ${ }^{10}$.

Daí surgem as pertinentes perguntas de Atílio Borón (2004, p. 120), cientista político argentino:

Devemos supor que os donos e/ou quem controlam estes novos e muito complexos e caros meios de produção irão ceder pacificamente sua propriedade e seu controle sobre os mesmos, jogando fora [arojando por la borda] os fundamentos mesmos de sua riqueza e de sua dominação política? Por que procederiam de tal maneira, inédita na milenar história das lutas de classes? Seriam conduzidos a trabalhar deste modo porque seus corações se enterneceriam ante a visão luminosa da multidão autoconstituída marchando jubilosamente até a sua liberação?

Se este não é o caso, qual seria a recomendação que poderiam fazer nossos autores ante a inevitável intensificação da luta de classes e da repressão política que seguramente desencadeariam as iniciativas emancipadoras da multidão?

\footnotetext{
${ }^{10}$ Permita-se um comentário crítico lateral aqui: o "êxodo" hardt-negriano, longe de ser algo de realmente original, parece muito o que os anarquistas individualistas (como os chamados "malucos de estrada" brasileiros) e os comunalistas (como os neo-hippies) já fazem há muito. Cabe perguntar - como o marxismo (e mesmo o budismo mahayana) o faz(em) - se tal é algo válido, em termos de revolução social (ou iluminação espiritual): garantir a sua própria libertação, enquanto os outrxs sofrem as agruras da dominação, da exploração e do extermínio - uma vez que as singularidades tem seu próprio tempo singular de luta, e um êxodo total, "messiânico", mostra-se drasticamente improvável entre singularidades radicais não-organizadas.
} 
N\&H não dão indicações concretas quanto a isso. A Multidão, seu ser, seu devir, são apresentados como conceitos basicamente filosóficos, sem maiores lastros em qualquer empiria, e sem construtos táticos e estratégicos no enfrentamento às barreiras e obstáculos que os operadores reais do dito Império irão colocar à emancipação geral da Multidão. Tudo soa como os próprios autores bem reconhecem - bastante profético e poético.

A própria cogitação de se realizar qualquer iniciativa organizativa mais consistente ainda que plural ou adequadamente não-coercitiva - é rechaçada. A dimensão espontânea da cooperação e da mobilização política e subversiva surge da imanência do ser multitudinário o que torna, a nosso sentir, tudo muito vago e indefinido.

Um crítico pós-marxista desse conceito hardt-negriano é o cientista político argentino radicado na Inglaterra Ernesto Laclau, falecido há alguns anos. Em sua obra "A Razão Populista" ele tece alguns comentários sobre aspectos da obra hardt-negriana a partir do primeiro volume da trilogia, "Império", mas que permanecem estrita e perfeitamente cabíveis mesmo após a publicação dos outros dois volumes. Por exemplo, Laclau explana como funciona a "criação da unidade da Multidão", qual o mecanismo unificador que a enseja.

Como funciona esse mecanismo unificador? De acordo com a análise de Império, ele não envolve qualquer tipo de mediação política particular, pois, de acordo com os autores, como é algo natural que os oprimidos se revoltem, sua unidade seria simplesmente a expressão de uma tendência espontânea à convergência. A unidade, como uma dádiva do céu, ocupa, na teoria de Hardt e Negri, o mesmo lugar que atribuímos [Laclau] à articulação hegemônica. (...)

O único princípio que garante a união da multidão em torno de um objetivo comum é aquilo que os dois autores denominam "ser contra": trata-se de ser contra tudo e em todos os lugares. O objetivo seria a deserção [êxodo] universal. Esse processo já estaria ocorrendo graças aos movimentos nômades, rizomáticos, das pessoas que atravessam fronteiras. (LACLAU, 2013, p. 340)

O tópico do livro onde o autor traça seus comentários é de fato muito informativo pra fins da crítica aventada: "Hardt e Negri: Deus Proverá". A homologia de alguns discursos e argumentos dos autores com pontos teológicos não é coincidência. O Êxodo do "povo escolhido" multitudinário, a Multidão enquanto "legião" demoníaca, o arquétipo de militante sendo São Francisco de Assis (tudo isso se encontra na trilogia de N\&H) não é mero acaso: a teoria hardt-negriana se furta de várias formas a uma crítica racional e metódica, dentre outras maneiras, pelo fato de se apresentar como postulações de caráter, mutatis mutandis, "profético". E profecias - ou postulações proféticas - são deveras difíceis de se criticar racionalmente, uma vez que se sustentam no terreno da teologia e, principalmente, da fé. 
Em Império, ela [a unidade a partir da heterogeneidade] resulta da tendência natural do povo de lutar contra a opressão. Não importa se denominamos essa tendência um presente dos Céus ou uma consequência da imanência. Deus sive Natura [Deus ou Natureza] ${ }^{11}$. O que importa é que a abordagem de Hardt e Negri desta questão os leva a simplificar demais o processo político. Se existe uma tendência natural à revolta, não há necessidade nenhuma construção política da revolta. (LACLAU, 2013, p. 340)

O resultado disso, portanto, é claro, segundo já disse Laclau (2013, p. 340): “como lutas verticalmente separadas não precisam ser ligadas horizontalmente, toda construção política desaparece".

O conceito do "ser contra" é dos mais problemáticos para o crítico:

Tomada literalmente, não faz qualquer sentido: as pessoas não estão contra tudo e em todos os lugares. (...)

A sociedade, entretanto, é muito mais complicada do que pretende essa formulação simplista. As pessoas nunca são apenas "contra", mas contra determinadas coisas e a favor de outras, e a construção de um "contra" mais amplo - uma identidade mais global - somente pode ser o resultado de uma extensa guerra política de posição que, é claro, pode fracassar. No que se refere a uma totalidade imperial desprovida de um centro - uma espécie de eternidade espinosana ( $\mathrm{sic}$-, da qual tivessem desaparecido os pólos internos de poder, isso [a guerra política de posição] já não faz mais sentido. (LACLAU, 2013, p. 342-343)

$\mathrm{N \& H}$, num arroubo profético, acabam por lançar ao mar toda uma construção política centenária da esquerda acerca de tática e estratégia, de construção contra-hegemônica, de disputa de poder. A renúncia multitudinária ao poder, a seu espaço e seu tempo, traria "como mágica" - ou como "milagre teológico-político" - a obsolescência e a irrelevância deste mesmo poder. O devir-messiânico da Multidão tudo resolve, tudo sara.

É, com a devida vếnia, o otimismo generoso e alegre daquele que crê. Se o crido existe ou não de fato, material e concretamente, na dimensão pobre e pouco poética da existência crua das pessoas sob o capitalismo, é um aspecto secundário.

Hardt e Negri tendem a simplificar excessivamente as tendências de unidade que operam no interior da multidão. Eles têm uma visão um tanto triunfalista e exageradamente otimista dessas tendências, embora não seja possível compreender, com base em suas colocações, se estas são reais ou virtuais. (LACLAU, 2013, p. 344)

${ }^{11}$ Referência à filosofia de Baruch de Espinosa. Vide ESPINOSA, 2003. 
Enfim, para Laclau, "os autores de Império não oferecem uma explicação coerente sobre a origem dos antagonismos sociais. O máximo que conseguem fazer é postular, como uma espécie de conatus espinosano (sic), a propensão natural e saudável do povo de se revoltar" (LACLAU, 2013, p. 344).

É, segundo o que se entende no presente trabalho, o espontaneísmo elevado à enésima potência, por obra de uma nova e multívoca "teologia" esquerdista; não mobilizadora e organizadora como aquela dita "da libertação", mote de luta para as massas latinoamericanas ainda hoje ${ }^{12}$, nem aquela antiga de Thomas Muntzer, nos idos da Reforma Protestante ${ }^{13}$ : ambas políticas, organizadoras da iniciativa de um enfrentamento sem estribeiras dos opressores de plantão. Aqui tem-se a apologia do "Êxodo", a nosso sentir atomístico e ensimesmado, da mônada ultrassingular que por obra divina, ou efeito imponderável da imanência, se encontra para a - fugaz e instável - luta "em comum".

Outros críticos continuam a destrinchar os conceitos hardt-negrianos, buscando não só seus lineamentos originários, mas sua (in)consistência intrínseca.

David Harvey, geógrafo britânico, produziu uma relativamente longa resenha crítica do último livro da trilogia de $\mathrm{N} \& \mathrm{H}$, onde analisa com atenção as proposições hardt-negrianas e pontua suas insuficiências (e acertos).

Quanto ao que aqui se trata - a concepção de "Multidão" - cabe trazer as ponderações de Harvey sobre o que o fundamento da "Multidão" hardt-negriana, qual seja, a "singularidade":

Singularidade (e disso eu realmente conheço) é um termo matemático que tem aplicações em física e na teoria da relatividade. (...) É um ponto em uma função que não é bem comportado, que pode explodir até o infinito, e que é em algum sentido irrepresentável. Exatamente por que indivíduos, pessoas, seres humanos, ou o que for devem ser reconceitualizados como singularidades em uma multidão não é claro para mim, exceto que, parece, o comportamento de singularidades é presumidamente não dado ou coberto pelo "campo de evento" ["event field"] que constitui a ordem social." (...) Então o que está sendo proposto aqui é um tipo de "ser de espécie" ["species being"] humano que tem capacidades até então não reconhecidas e, talvez ainda mais importante, irrepresentável na história humana. A singularidade irrepresentável é o elemento fundador na multidão. (HARVEY, 2009, p. 258)

Harvey, pois, se encontra um tanto resistente quanto às razões de se utilizar uma concepção matemática para definir um dado processo ou fenômeno social. O que seria a

\footnotetext{
${ }^{12}$ GALILEIA, 1982; LÖWY, 2016.

${ }^{13} \mathrm{BLOCH}, 2002$.
} 
singularidade "sociológica"? Qual é a razão de ser - ou a verossimilhança - da qualidade da "irrepresentabilidade" desta singularidade tomada como oblíquo indicador do humano?

Talvez estejamos, pois, dizendo de “desrazões de ser". O irrepresentável, longe de passar por referenciais racionais, seria mais um construto intelectual um tanto obscuro, não razoável (ou mesmo voluntariamente irrazoável/irracional), como por vezes costuma surgir no pensamento pós-moderno. Não é outra a sensibilidade de Harvey (2009, p. 258), especulando sobre esse pitoresco surgimento da singularidade no campo da teoria - e da luta - social:

Meu palpite é que é precisamente esta irrepresentabilidade que torna a noção tão importante e atraente. Há algo empoderador em pensar em mim mesmo como irrepresentável e capaz irromper até o infinito! Mas esta irrepresentabilidade faz com que toda a discussão fique vaga, opaca, e frustrantemente abstrata. É difícil ter uma conversa sensata sobre algo que é irrepresentável.

Como bem reivindicam tantos teóricos devedores de Jacques Derrida, Michel Foucault et al, a discussão racional, minimamente analítica, fica obstada de plano. Ser irrepresentável, mais do que ser um conceito que busca compreender o real, é uma proposição "trancada em si”, impassível de encontro e análise metódica, um "porta-estandarte" teórico para o ensimesmamento que por vezes é moeda corrente no pós-modernismo - agora, com ares de revolta (referenciada no indivíduo singular) contra o sistema.

Contudo, ainda insistindo em trazer a discussão para o possível intercâmbio linguístico e teórico, Harvey questiona uma das consequências postuladas para a existência imanente da singularidade hardt-negriana: a mutabilidade radical e total das identidades na e pela singularidade que (supostamente) se apresenta no mundo:

Esta noção de singularidade carrega [carry over] para a visão revolucionária [a acepção de] que podemos na verdade nos despir de qualquer e de todos os sinais de identidade - racial, de classe, de gênero, sexual, étnico, religioso, e territorial - e de alguma forma nos despir até um estado de puro ser do qual podemos nos reconstruir de acordo com princípios inteiramente diferentes. Nós literalmente temos que nos esquecer de quem somos, onde nascemos, e de como nossa sociabilidade [sociality] foi formada através de experiências de vida geograficamente embasadas [grounded]. Mas aqui é onde o problema de nossas identidades como, por exemplo, produtores e consumidores e como seres geograficamente embasados entra em cena. O problema não é que nós possamos de fato abrir mão de nossas identidades sociais baseadas em classe, raça, gênero etc. mais facilmente que abriremos mão de nossos IPods e telefones celulares e identidades associadas com onde e como vivemos, mas não há como podermos viver sem produzir e consumir e não há como podermos viver fora da geografia. Essas identidades não podem nunca serem abandonadas da forma em que eu posso em princípio abandonar minha identidade de classe (o que é, obviamente, inteiramente diferente de dizer que 
nossos hábitos de consumo não podem mudar ou que não podemos mudar de localidade). (HARVEY, 2009, p. 258)

Harvey, então, resistindo aos anseios filosóficos de fluxo de intercâmbios e de abandonos (êxodos) totais, indica que certas identidades marcam o ser, agenciam-no e - de certa forma - o aprisionam num plexo de referenciais mínimos. Ninguém pode se despir de tudo o que o determina ou condiciona. O que se pode é, ativa e conscientemente, questionar e buscar, em meio a determinações e condicionamentos, superar entraves e limitações e se repropor novos limites, novos agenciamentos, em uma relação dialética com estados anteriores - eis a Aufhebung. Uma dinâmica razoável, mas só compreensível com o instrumental da dialética marxista - algo que N\&H denunciam em sua obra como insuficiente, enquanto culpada do crime de "hegelianismo". Em suma, na imanência profética da Multidão de singularidades, só o milagre da transmutação dos homens e mulheres historicamente considerados em puro ser é algo digno de afirmação.

\section{Algumas conclusões}

Com efeito, a noção de "Multidão" advogada por N\&H como o novo "sujeito" revolucionário, como uma profusão de singularidades mutantes e magicamente solidárias é, segundo as conclusões às quais a pesquisa chegou, bastante idealizada, pouco calcada em empiria rigorosamente captada e tratada, e ignora em profundidade a maior parte do conhecimento humano já desenvolvido no que toca à teoria crítico-revolucionária.

Em nome de uma postulação do "Novo", de uma nova "heresia político-filosóficoteológica", o lastro empírico consequente que se presta a embasar uma análise conjuntural e estrutural pertinente parece ser deixado de lado, nas espirais e circunvoluções do discurso e da prática (tendencialmente imobilista, no mais das vezes) pós-modernos - aos quais a teorização de $H \& N$ se filia, mais ou menos ostensivamente. A demão de tinta vermelha não esconderia o jogo multicolor e ininterruptamente recombinante da teoria "comunista" pós-moderna hardtnegriana.

Muito ainda se poderia falar do tema da "Multidão": seu suposto extremismo individualista, até em comparação ao anarquismo mais libertário; sua genealogia enquanto frágil desenvolvimento do instrumental teórico do operaísmo italiano da década de 70; seu suposto descolamento orgânico, militante e concreto com as lutas reais (arriscadas, pesadas) dos mais diversos grupos oprimidos diuturnamente; seu DNA hostil de facto ao marxismo e ao 
seu método próprio; seu caráter fragmentário, pouco afeito à geração de poder político real pela unificação concreta de lutas sob coordenações mais ou menos organizadas; o autorreferenciamento tanto solipsista da singularidade componente da Multidão (e de seu correspondente sociológico: o "militante" pós-moderno "esquerdista")...

Enfim. Eis uma pauta para futuras investigações. Por ora, fica o exposto supra.

\section{Referências}

BIDET, Jacques. A multidão perdida no império. In: Crítica Marxista. Campinas: Revan, 2004. n. 19.

BLOCH, Ernst. Thomas Müntzer - teologo de la revolución. Madri: Antonio Machado, 2002.

BORÓN, Atilio A. Imperio \& imperialismo: una lectura crítica de Michael Hardt y Antonio Negri. 5.ed. Buenos Aires: CLACSO, 2004.

BULL, Malcolm. You can't build a new society with a Stanley knife. In: London Review of Books. Londres: London Review of Books, 2001. v. 23, n. 19.

COCCO, Giuseppe. Giuseppe Cocco fala sobre o conceito de multidão e os movimentos sociais. Revista Eletrônica Portas. Rio de Janeiro, v. 1, n. 1, dez. 2007. Disponível em $<$ http://www.acicate.com.br/portas/giuseppe.pdf $>$. Acesso em: 01 nov. 2020.

COCCO, Giuseppe; NEGRI, Antonio. Glob(AL): biopoder e lutas em uma América Latina globalizada. Rio de Janeiro: Record, 2005.

DICIONÁRIO ONLINE DE PORTUGUÊS. Parúsia. Disponível em: $<$ https://www.dicio.com.br/parusia-2/>. Acesso em 01 nov. 2020

EAGLETON, Terry. As ilusões do pós-modernismo. Rio de Janeiro: Jorge Zahar, 1998.

EAGLETON, Terry. Depois da teoria - um olhar sobre os Estudos Culturais e o pósmodernismo. Rio de Janeiro: Civilização Brasileira, 2016.

ESPINOSA, Baruch de. Tratado teológico-político. São Paulo: Martins Fontes, 2003.

FANON, Frantz. Os condenados da terra. Juiz de Fora: Editora UFJF, 2006.

GALILEIA, Segundo. Teologia da libertação: ensaio de síntese. 3. ed. São Paulo: Edições Paulinas, 1982.

HARDT, Michael; NEGRI, Antonio. Império. Rio de Janeiro: Record, 2001.

HARDT, Michael; NEGRI, Antonio. Multidão: guerra e democracia na era do Império. Rio de Janeiro: Record, 2005. 
HARDT, Michael; NEGRI, Antonio. Bem-estar comum. Rio de Janeiro: Record, 2016.

HARVEY, David. A condição pós-moderna: uma pesquisa sobre as origens da mudança cultural. São Paulo: Edições Loyola, 1992.

HARVEY, David. Commonwealth: an exchange. In: Artforum. Nova Iorque: Artforum International Magazine, 2009. n. nov. 2009.

JAMESON, Fredric. A virada cultural: reflexões sobre o pós-moderno. Rio de Janeiro: Civilização Brasileira, 2006.

JAMESON, Fredric. Postmodernism - or, the cultural logic of late capitalism. Durham: Duke University Press, 1991.

KOHAN, Néstor. O Império de Hardt \& Negri: para além das modas, "ondas" e furores. In: BORÓN, Atilio (org). Filosofia Política Contemporânea: Controvérsias sobre Civilização, Império e Cidadania. Buenos Aires: CLACSO, 2006.

LACLAU, Ernesto. A razão populista. São Paulo: Três Estrelas, 2013.

LÖWY, Michael. O que é cristianismo da libertação? Religião e política na América Latina. São Paulo: Expressão Popular, 2016.

MARX, Karl. Grundrisse: manuscritos econômicos de 1857-1858 - esboços da crítica da economia política. São Paulo: Boitempo, 2011.

MARXWIKI. Lumpenproletariat. Disponível em: $<$ https://web.archive.org/web/20100717131508/http://machines.pomona.edu/marxwiki/index. php/Lumpenproletariat>. Acesso em 01 nov. 2020.

MASO, Juan Dal. Toni Negri o la decadência del autonomismo. In: IPS Blog de Debate. Disponível em <http://www.ips.org.ar/?p=986 $>$. Acesso em: 01 nov. 2020.

MOUFFE, Chantal. Por um populismo de esquerda. São Paulo: Autonomia Literária, 2019. NEGRI, Antonio. Para uma definição ontológica da Multidão. In: Lugar Comum. Rio de Janeiro, n. 19-20, jan-jun. 2004. Disponível em $<$ http://uninomade.net/wpcontent/files_mf/113103120455output19-20.pdf>. Acesso em: 01 nov. 2020.

TURCHETTO, Maria. The Empire strikes back: on Hardt and Negri. In: Historical Materialism. Leiden: Koninklijke Brill, 2003. v. 11. n. 1.

UNINÔMADE BRASIL. Quem somos. Disponível em: <http://uninomade.net/quemsomos/>. Acesso em: 01 nov. 2020.

ZIZEK, Slavoj. A tinta vermelha: discurso de Slavoj Zizek aos manifestantes do movimento Occupy Wall Street. In: Blog da Boitempo. Disponível em $<$ http://blogdaboitempo.com.br/2011/10/11/a-tinta-vermelha-discurso-de-slavoj-zizekaos-manifestantes-do-movimento-occupy-wall-street/>. Acesso em: 01 nov. 2020. 
Data de recebimento: 13.05 .2021

Data de aprovação: 22.07.2021 